\title{
The effects of dietary protein level during food restriction on carcass and non-carcass components, digestibility and subsequent compensatory growth in lambs
}

\author{
G. R. Iason and A. R. Mantecont \\ Macaulay Land Use Research Institute, Craigiebuckler, Aberdeen AB9 2QL
}

\begin{abstract}
The effect of proportion of dietary rumen non-degradable protein during food restriction on the weight of components of the digestive tract, carcass and subsequent growth was investigated in 37 Scottish Blackface wether lambs (initial live weight, $25 \mathrm{~kg}$ ). Lambs were given individually ad libitum for 4 weeks a complete pelleted diet containing $150 \mathrm{~g} / \mathrm{kg}$ white fish-meal (HP, 10.4 MJ metabolizable energy (ME) per kg dry matter (DM), $195 \mathrm{~g}$ crude protein $(C P)$ per $\mathrm{kg} D M$ ). Seven lambs were then slaughtered and 15 were switched to a diet containing no white fish-meal (LP, 10.4 MJ ME per $\mathrm{kg}$ DM, $122 \mathrm{~g}$ CP per $\mathrm{kg}$ DM) offered at $18 \mathrm{~g}$ DM per $\mathrm{kg} M$ per day, i.e. sufficient to maintain constant live weight. A further 15 continued to receive the HP diet at the same rate as the lambs given LP. After 6 and 12 weeks, five lambs on each diet were slaughtered. At 12 weeks the remainder received the HP diet ad libitum for a further 7 weeks before slaughter. During food restriction on both diets, the proportion of live weight formed by the carcass, the dissected components and the chemical composition remained the same as in the initial slaughter group. The relative weight of the non-carcass components fell during food restriction on both diets. There was a significant $(\mathrm{P}<0.05)$ interaction between slaughter date and dietary treatment for reticulo-rumen weight as a proportion of empty body weight (EBM); it was smaller in lambs on the HP diet after 12 weeks of restriction (HP: 0.022, LP: 0.026). A similar pattern was observed for the small intestine and the total digestive tract. During the 7 weeks of realimentation, lambs previously on HP and LP diets had similar intakes (1343 and $1208 \mathrm{~g}$ DM per day) and digestive tract components, body components and chemical composition of carcass and non-carcass components were all unaffected by previous treatment. The apparent digestibility of CP of the HP diet was greater than that of the LP diet although it was overall less degradable in the rumen. When both groups of lambs were realimented on the HP diet, there were no differences in the apparent digestibility of any of the dietary components. A high dietary protein: energy ratio during restriction reduced the weight of some of the components of the digestive tract but did not significantly affect carcass composition. The effect did not persist following realimentation and did not significantly influence subsequent performance.
\end{abstract}

Keywords: dietary protein, food restriction, growth, lambs.

\section{Introduction}

Food restriction followed by compensatory growth provides a means of delaying growth and maturation of animals and in the case of sheep production systems in the United Kingdom provides the possibility of a more even supply of lamb to the market. Many studies have concentrated on applied aspects of carcass composition resulting from

+ Present address: CSIC, Estacion Agricola Experimental, 24071, Leon, Spain. compensatory growth whilst the mechanisms underlying the phenomenon are not well understood. It is, however, intuitively expected that changes in nutritional conditions during food restriction provide the background against which changes in animal performance during realimentation take place. Several parameters of the food restriction period have been shown to influence the compensatory growth response including the duration of food restriction and the severity of restriction. These responses vary with the age or stage of maturity at which the restriction is applied 
(O'Donovan, 1984; Ryan, 1990). The nature of the food restriction, e.g. restriction of protein or energy has also been identified as affecting the extent and composition of the compensatory growth response (Wilson and Osbourn, 1960).

A previous study showed rapid, short-term increases in the apparent digestibility of diets on realimentation and this was likely to have been due to the increase in intake and content of the digestive tract (Asplund, Hedrick and Haugebak, 1975). Level of intake also affects the thickness and weight of the rumen wall (Fell and Weekes, 1975).

In order to investigate the mechanisms of compensatory growth, this study varied the dietary protein: energy ratio during the period of food restriction, providing two diets similar in all respects except the addition of non-rumen degradable protein to one of them. The rationale for the approach adopted was to vary the diet quality of two groups of lambs during a period of restriction to constant live weight whilst simultaneously holding their intake constant. Changes in digestibility and dimensions of the components of the digestive tract were measured during restriction and after realimentation. It was intended that this procedure would permit comparisons of the nutritional changes occurring due to diet quality during restriction, independently of differences in intake.

\section{Material and methods}

Experimental design

Thirty-seven castrated Scottish Blackface lambs from the Macaulay Land Use Research Institute's Sourhope Research Station, Roxburghshire were housed from weaning at the end of August. All lambs were given food ad libitum until the 26 September with a high protein (HP) complete diet which incorporated finely chopped straw into $10 \mathrm{~mm}$ diameter pellets (Table 1), when an initial group of seven were slaughtered (group I). From this date 15 lambs remained on the $\mathrm{HP}$ diet whilst 15 were switched to a low protein diet (LP) with no fish meal but similar metabolizable energy (ME) content (Table 1). The intakes of the LP group were calculated on an individual lamb basis to maintain them at a constant live weight, the intakes being about $18 \mathrm{~g}$ dry matter (DM) per kg M (see Doney, Milne, Maxwell, Sibbald and Smith, 1988). The intakes of the HP group were then adjusted to equal the average of the LP group. Groups of five lambs per dietary treatment were then slaughtered after 6 weeks and 12 weeks of food restriction (6R and 12R slaughter groups). The remaining five lambs per treatment were then all offered the HP diet ad libitum for a further 7-week
Table 1 The ingredients and composition of the low protein (LP) and high protein (HP) diets

\begin{tabular}{lcc}
\hline \hline & LP & HP \\
\hline Ingredients (g/kg) & & \\
Barley straw (chopped) & 150 & 150 \\
Sugar-beet pulp & 350 & 250 \\
Dried grass & 450 & 400 \\
Fish meal & & 150 \\
Vitamin/mineral/molasses & 50 & 50 \\
Composition & & \\
Dry matter (g/kg) & 871 & 872 \\
Organic matter (g/kg DM) & 953 & 949 \\
Crude protein (g/kg DM) & 122 & 195 \\
ADF (g/kg DM) & 293 & 280 \\
Estimated ME (MJ/kg DM) & $10 \cdot 4$ & $10 \cdot 4$ \\
Estimated undegradable & & \\
protein (g/kg DM) & $19 \cdot 8$ & $79 \cdot 7$ \\
\hline \hline
\end{tabular}

realimentation period before slaughter (AD slaughter groups).

\section{Animal measurements}

All lambs were individually penned throughout and the food offered and refused was weighed daily and live weight was recorded weekly. Lambs were shorn prior to slaughter and their fleeces weighed. At slaughter, the total digestive tract was weighed both full and empty. The reticulo-rumen, omasum, abomasum, small intestine and large intestine were separated and their surrounding fat depots were removed by hand. The components were washed and dried with paper towels before being weighed. The pelt, feet, head and internal organs were weighed separately and combined with the components of the gastro-intestinal tract to form the non-carcass component. Note that empty body weight (EBM) included fleece and blood which were not incorporated into the non-carcass component. The complete carcass was weighed 'hot', chilled and split medially. One half was retained and stored at $-20^{\circ} \mathrm{C}$ for subsequent dissection into three components, muscle plus associated (intermuscular) fat, subcutaneous fat and bone. These were weighed and recombined for mincing. The minced carcass and non-carcass components were subsampled and were chemically analysed for fat by soxhlet extraction, ash, protein by a Kjeldahl technique and water.

\section{Nutritional measurements}

Two further groups, each of five lambs were placed on the same feeding regimes as the slaughter groups. During both restriction and realimentation, these groups were placed in standard metabolism crates fitted with urine separators and collectors for faeces. Lambs were given 14 days acclimatization to the 
metabolism crates, 5 of which were prior to the change over from the initial HP ad libitum feeding period to the restricted diets (HP and LP). As with the slaughter groups, intake was measured continuously and total collections of faeces were made for 3 days, beginning 1 week after the change over. This was repeated after 4 and 8 weeks of restriction but with only 5 days prior acclimatization to the metabolism crates. This procedure was repeated during realimentation, after the reversion to ad libitum feeding on the HP diet, with measurements again being made 1,4 and 8 weeks after the change over. It would have been preferable to have measured apparent digestibility over a longer period but if digestibility was changing within the period of measurement then any differences between weeks would not have been observed. Faeces were subsampled, freeze-dried, milled and stored at $-20^{\circ} \mathrm{C}$ prior to analysis for aciddetergent fibre (ADF), organic matter $(\mathrm{OM})$ and total nitrogen.

\section{Statistical analysis}

Standard analysis of variance (ANOVA) techniques were used using GENSTAT (Lawes Agricultural Trust, 1984). Any data derived from the initial slaughter group (I) were entered in a category within both dietary treatments. Under these circumstances the statistic of primary interest is the interaction between slaughter group (or time) $\times$ dietary treatment. Specific post-hoc comparisons between groups were made using the LSD test (Snedecor and Cochran, 1980).

\section{Results}

Animal performance

During the restriction period of 12 weeks, the food intake and live weight of the lambs were successfully controlled. During the 7-week period of
Table 2 Animal performance during the period of realimentation with ad libitum high protein diet

\begin{tabular}{lccc}
\hline \hline & LP & HP & s.e.d. \\
\hline $\begin{array}{l}\text { Live-weight gain (g/day) } \\
\text { Live-weight gain (g/kg }\end{array}$ & 178 & 194 & $26 \cdot 3$ \\
$\begin{array}{l}\mathrm{M}^{0.75} \text { per day) } \\
\text { Intake (g DM per day) }\end{array}$ & 13.2 & 13.7 & 2.09 \\
$\begin{array}{l}\text { Food conversion ratio } \\
\text { (g DM food per g M gain) }\end{array}$ & 7.18 & 7.04 & 0.915 \\
\hline \hline
\end{tabular}

realimentation on the ad libitum $\mathrm{HP}$ diet, there were no significant differences in live-weight gain, intake or food conversion ratio, associated with dietary treatment during food restriction (Table 2).

Body components and chemical composition

The successful maintenance of the lambs at constant live weight during food restriction is confirmed by the consistency of live weight at slaughter and fleecefree EBM in slaughter groups I and R6 and R12 on both HP and LP diets (Table 3). Absolute weights of carcass and non-carcass components did not differ significantly between the I and R6 and R12 groups, but had increased considerably after realimentation (Table 3). The proportion of live weight formed by carcass (killing-out proportion) also remained constant during LP and HP dietary restrictions. The proportion of the non-carcass components in the live weight fell significantly during food restriction on both diets as compared with the I slaughter group $(P<0.05)$, the lower values persisting in the R6 and R12 groups (Table 3).

The three dissected components of the carcass, subcutaneous fat, bone and muscle plus associated fat also showed the typical consistency between the I

Table 3 The live weights and weights of the major body components of lambs in each slaughter group. The s.e.d. derives from the interaction term in the two-way ANOVA of slaughter group $X$ restriction diet

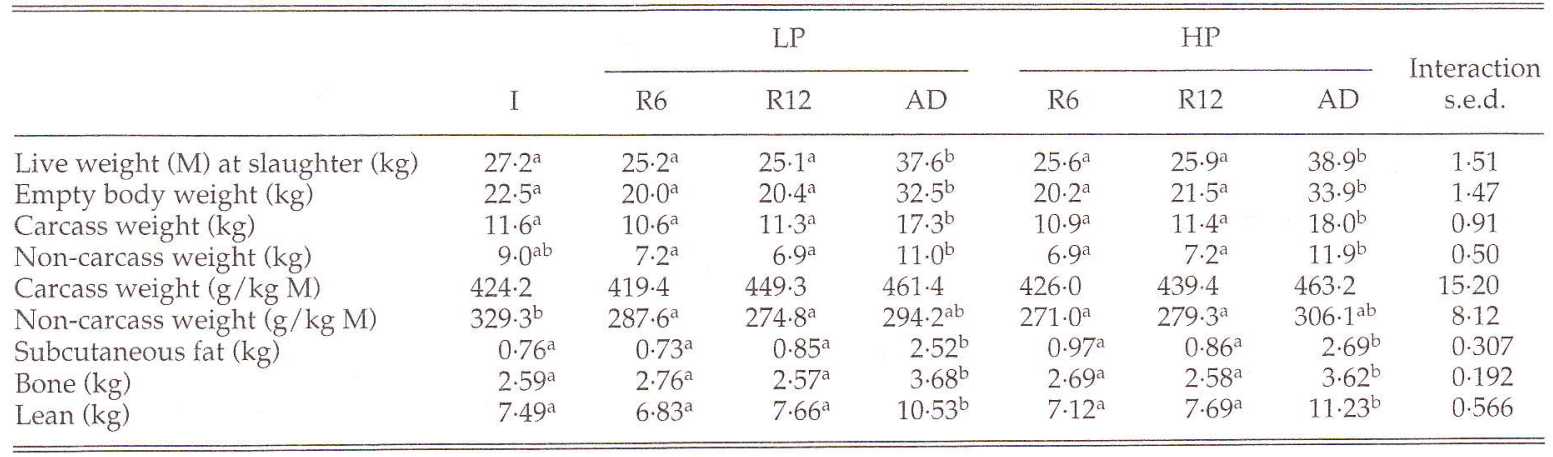

$a, b$ Different superscripts denote significant differences within rows $(P<0 \cdot 05)$. 
Table 4 The chemical composition of the carcass and non-carcass components of each slaughter group according to diet during restriction. The s.e.d. derives from the interaction term in the two-way ANovA of slaughter group $\times$ restriction diet

\begin{tabular}{|c|c|c|c|c|c|c|c|c|}
\hline & \multirow[b]{2}{*}{ I } & \multicolumn{3}{|c|}{ LP } & \multicolumn{3}{|c|}{$\mathrm{HP}$} & \multirow{2}{*}{$\begin{array}{c}\text { Interaction } \\
\text { s.e.d. }\end{array}$} \\
\hline & & R6 & $\mathrm{R} 12$ & $\mathrm{AD}$ & R6 & R12 & $\mathrm{AD}$ & \\
\hline \multicolumn{9}{|c|}{ Carcass $(\mathrm{g} / \mathrm{kg})$} \\
\hline water & $626 \cdot 9^{a}$ & $603.9^{a}$ & $584 \cdot 4^{a}$ & $556 \cdot 4^{\mathrm{b}}$ & $620 \cdot 7^{a}$ & $591 \cdot 5^{a}$ & $547 \cdot 0^{\mathrm{b}}$ & $18 \cdot 46$ \\
\hline fat & $126 \cdot 7^{a}$ & $147 \cdot 3^{a}$ & $153 \cdot 3^{\mathrm{a}}$ & $202 \cdot 0^{a}$ & $138 \cdot 6^{\mathrm{a}}$ & $161 \cdot 9^{\mathrm{a}}$ & $218 \cdot 4^{\mathrm{b}}$ & 19.83 \\
\hline ash & $55 \cdot 5$ & $58 \cdot 5$ & $56 \cdot 1$ & $47 \cdot 0$ & $48 \cdot 3$ & $55 \cdot 6$ & $50 \cdot 5$ & 4.94 \\
\hline water & $680 \cdot 5^{\mathrm{a}}$ & $662 \cdot 3^{a}$ & $636 \cdot 8^{\mathrm{ab}}$ & $626 \cdot 7^{\mathrm{b}}$ & $673 \cdot 1^{a}$ & $692 \cdot 6^{a}$ & $613 \cdot 7^{\mathrm{b}}$ & $24 \cdot 53$ \\
\hline fat & $109 \cdot 8^{a}$ & $126 \cdot 5^{a}$ & $146 \cdot 3^{a b}$ & $161 \cdot 4^{\mathrm{b}}$ & $115 \cdot 1^{\mathrm{a}}$ & $106 \cdot 6^{\mathrm{a}}$ & $173 \cdot 0^{\mathrm{b}}$ & 19.76 \\
\hline ash & $38 \cdot 1^{\mathrm{a}}$ & $42 \cdot 8^{\mathrm{b}}$ & $38 \cdot 1^{\mathrm{a}}$ & $37 \cdot 0^{\mathrm{a}}$ & $42 \cdot 8^{b}$ & $41 \cdot 7^{b}$ & $35 \cdot 6^{\mathrm{a}}$ & 3.02 \\
\hline protein & $171 \cdot 6$ & $167 \cdot 9$ & 178.8 & $174 \cdot 8$ & $169 \cdot 1$ & $159 \cdot 1$ & $177 \cdot 7$ & $10 \cdot 90$ \\
\hline
\end{tabular}

a,b Different superscripts denote significant differences within rows $(P<0.05)$.

slaughter group and the R6 and R12 groups on both restriction diets.

Although the relative size of the non-carcass components fell significantly on food restriction (Table 3), their chemical composition remained constant between the I and the R6 and R12 slaughter groups (Table 4). The only change was a slight increase in the proportion of ash, which subsequently fell again in group LP-R12 and on realimentation in the HP-AD group. On realimentation the proportion of fat in the noncarcass component increased significantly $(P<0 \cdot 05)$ and water decreased significantly $(P<0.05)$ in the HP group but not in the LP group.

The chemical composition of the carcass components was constant between the I slaughter groups and the R6 and R12 slaughter groups regardless of the diet during restriction (Table 4). On realimentation the proportion of fat increased and the proportion of water decreased $(P<0.05)$ in lambs previously restricted on both $\mathrm{HP}$ and LP diets.

\section{Size of the gastro-intestinal organs}

Weights of the gastro-intestinal tract and its components are expressed as proportions of EBM, since EBM did not vary with dietary treatment and increased on realimentation equally, regardless of the dietary treatment during restriction. When the initial slaughter group was compared with the restricted groups, the overall weight of the empty fat-free gastro-intestinal tract declined on restriction (Figure 1). The weight of the total digestive tract increased on realimentation but did so in proportion to growth of the empty body, and in the $\mathrm{AD}$ slaughter groups did not recover its large size relative to EBM; it remained lower than in the I group. The significant reduction in relative weight of the gastro-intestinal tract $(P<0.05)$ was more marked in the lambs restricted on the HP diet after 6 weeks of restriction, but by 12 weeks those restricted on the LP diets were equally small. This result for the overall gastro-intestinal tract can be explained by the changes in relative sizes of its two largest components, the reticulo-rumen and the small intestine. The reticulo-rumens of the lambs restricted on the HP diet for 12 weeks (R12) were significantly smaller than those of both the I group $(P<0.05)$ and those restricted for 12 weeks on an LP diet (Figure 1). The small intestine also became smaller during restriction and remained small during realimentation in comparison with the I group $(P<0.05)$. Neither large intestine, omasum nor abomasum varied in size relative to EBM between the slaughter groups.

Apparent digestibility during food restriction and realimentation

The apparent digestibility of the ADF and to a lesser extent the OM components of both LP and HP diets declined from the 1 st week after restriction to the 4 th and 8th weeks $(P<0.05$ and $P<0.1$ respectively, Figure 2). The apparent digestibility of crude protein did not vary with time during restriction but the apparent digestibility of crude protein of the HP diet was consistently greater than that of the LP diet $(P<0.001)$. In addition to the imposition of food restriction on those lambs in the LP dietary treatment, this group also received a change in dietary protein : energy ratio. This might have been expected to have led to more of a disruption in digestive ability of the LP restricted group than the $\mathrm{HP}$ group which underwent only restriction without qualitative dietary change. However, there were no 


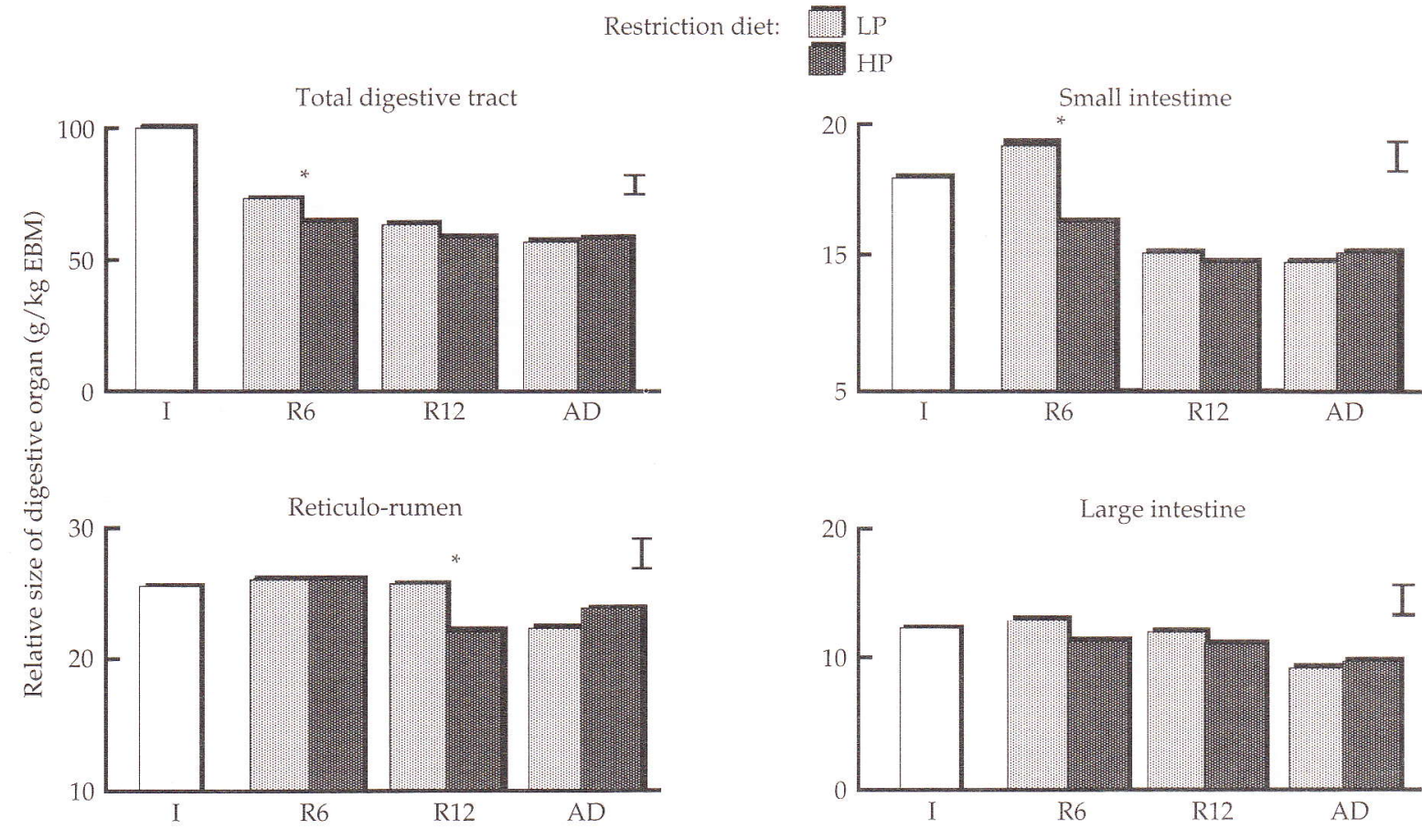

Figure 1 The weights of the fat-free components of the gastro-intestinal tract of lambs in each slaughter group as a proportion of empty body-weight (EBM). Bars represent the s.e.d. between means. *: significant difference $(P<0.05$ LSD test) between dietary treatments within slaughter groups.

significant restriction diet $X$ period interaction effects for the apparent digestibility of any of the dietary components measured.

The difference in apparent digestibility of crude protein in the HP and LP diets which was evident during the restricted period, did not persist when all lambs were realimented on the HP diet (previous diet LP: 0.707; previous diet HP: $0.734, P>0.05$ (Figure 2)). There were no significant differences in the apparent digestibility of ADF or OM of the ad libitum HP realimentation diet according to the group's previous restriction diet. There was no change with time, weeks 1,4 and 8 , in apparent digestibility of any of the dietary components during realimentation.

\section{Discussion}

\section{Changes during restriction}

The overall picture presented by the data shows the carcass as being constant in both size and composition during food restriction on the HP and LP diets. This is in contrast with the data of Murray and Slezacek (1988a) who found dissectable carcass fat to increase during a period of constant live weight. The converse has also been shown, in that when energy supply to a ruminant is restricted, and a source of non-rumen-degradable dietary protein is provided, net body fat can be used to fuel protein deposition (Fattet, Hovell, Ørskov, Kyle, Pennie and Smart, 1984). These conditions of restriction of exogenous energy along with added dietary fish meal were similar to those in our HP-restricted group. We found no evidence of enhanced protein deposition in this group of young lambs, a result which confirms the current evidence that the effect only occurs in overfat animals (Vipond, King, Ørskov and Wetherill, 1989; Chowdhury, Ørskov, Hovell and Mollison, 1991).

Previous studies have shown a decline in the size of the digestive tract (Murray and Slezacek, 1988b), especially the reticulo-rumen and small intestine (Murray and Slezacek, 1980) during food restriction. In this experiment the reticulo-rumen became smaller and the small intestine decreased in size more rapidly on the HP than on the LP diet. This demonstrates that the changes in the gastro-intestinal components during food restriction are related to the 
(a) Digestibility during food restriction
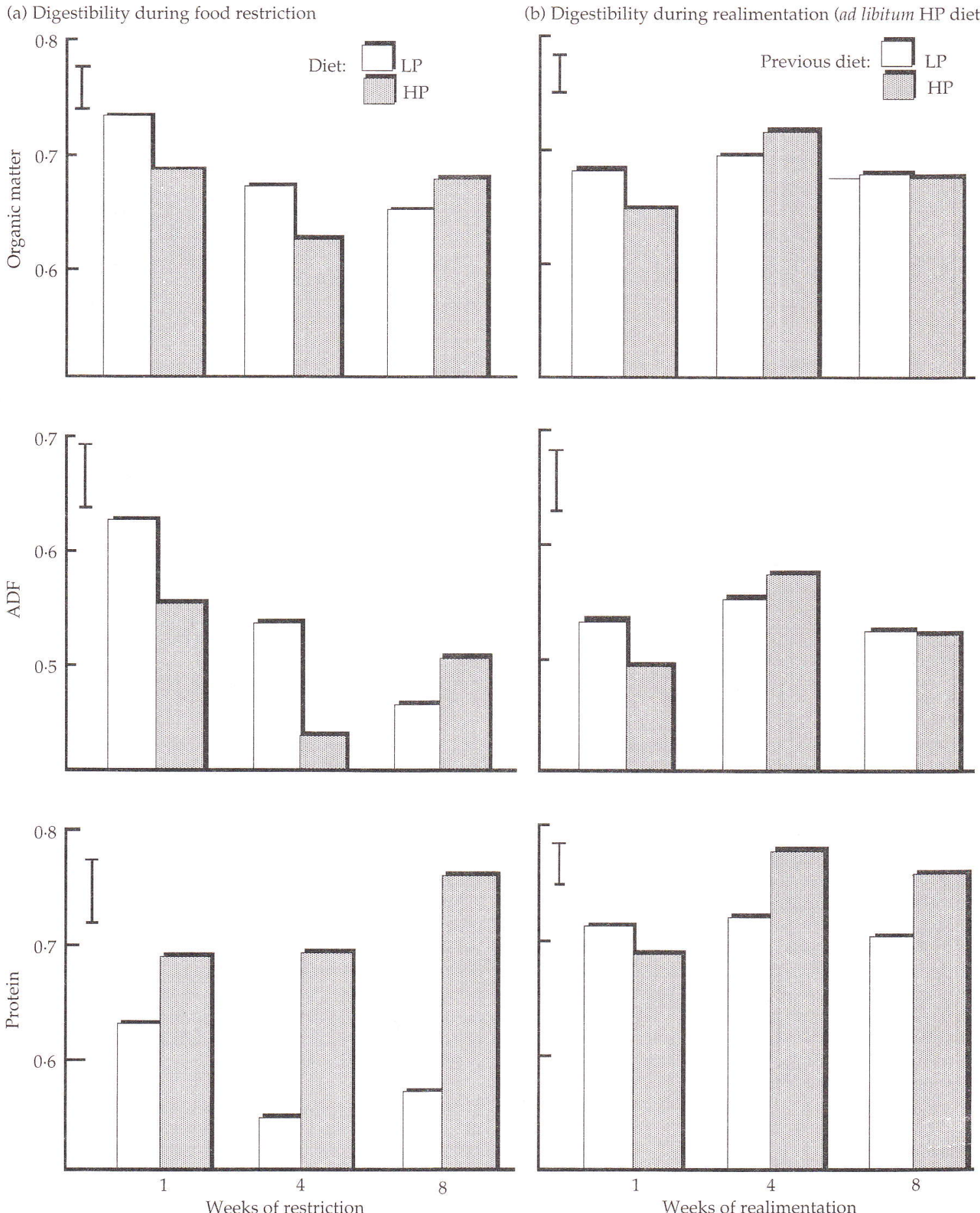

Figure 2 The apparent digestibility in vivo of organic matter, acid-detergent fibre (ADF) and protein components of (a) the low protein (LP) and high protein (HP) diets during restriction and (b) of the HP diet during realimentation of the two groups. Bars represent the s.e.d. between means. 
quality of the diet during this time. Weights of digestive organs, especially the reticulo-rumen, are determined in part by food intake (Fell and Weekes, 1975), but this was held the same on the HP and LP diets during restriction in this experiment. Furthermore the ADF levels in the two diets were also similar and we can dismiss physical abrasion as being the stimulus for the difference in rumen weights during restriction on the two diets. There were no differences in apparent digestibility of $\mathrm{OM}$ or ADF of the LP and HP diets during restriction. Although we cannot distinguish between cause and effect, the smaller rumens of the lambs restricted on the HP diet were probably associated with shorter rumen retention times. The apparent digestibility of the protein fraction of the $\mathrm{HP}$ diet during restriction was greater for the HP restricted lambs. This may have been due to the slightly greater amounts of rumen-degradable protein in the HP diet, or to ruminal, but most likely, post-ruminal, digestion of the added fish meal.

\section{Changes on realimentation}

The main responses on realimentation were, as occurred during restriction, in terms of differences in the non-carcass components. Those lambs previously restricted on the HP diet had a higher increment in proportion of fat in their non-carcass components than those previously restricted on the LP diet. The overall weight of the non-carcass components and all of the gastro-intestinal organs were similar in the AD slaughter groups previously restricted on different diets. Some studies have shown a rapid increase in protein deposition in the carcass soon after realimentation followed by greater increments in fat deposition later in the finishing period (Turgeon, Brink, Bartle, Klopfenstein and Ferrell, 1986; Iason, Mantecon, Milne, Sim, Smith and White, 1992). On realimentation for 7 weeks with an HP diet after restriction on LP or HP diets there was no difference between groups in carcass growth or carcass composition, except for a greater carcass fat increment in those previously restricted on an HP diet. Overall animal performance was at levels expected from animals showing compensatory growth after restriction, but did not differ between lambs according to their dietary protein: energy ratio during previous restriction. Intake and liveweight gain during realimentation were both greater in those previously receiving the $\mathrm{HP}$ diets, but not significantly so. Hence, given the diets and treatments in this experiment there was no effect of dietary protein: energy ratio during restriction on carcass production, animal performance or digestive ability, and the changes effected by diet quality on non-carcass and especially gastro-intestinal tract dimensions were short-lived.
The rôle of the gastro-intestinal tract in compensatory growth

There are several current hypotheses as to how changes in size and activity of the gastro-intestinal tract during food restriction can influence the subsequent compensatory growth. These include the atrophication of the gastro-intestinal tract due to food restriction (Murray and Slezacek, 1980), leading to a reduced metabolic requirement for maintenance of this highly energy-demanding tissue (Ryan, 1990). This would spare energy for more body growth immediately on realimentation. Despite holding intake constant in the restricted groups on both diets, the HP lambs developed lighter reticulo-rumens thant the LP lambs. The prediction would thus have been that compensatory growth on realimentation would have been greater in the HP lambs due to their smaller reticulo-rumen size. Although the HP restricted lambs had greater live-weight gains and increases in EBM on realimentation than the LP restricted lambs and the result was in the predicted direction, it was not statistically significant. We can hence neither refute nor confirm the hypothesis. Since there was no difference in voluntary food intake on realimentation between the two groups, it is unlikely that rumen size, smaller in the HP restricted group, limited food intake. Alternatively our measurement of the weight of reticulo-rumen may not be a reflexion of reticulo-rumen volume but may be associated with the density or degree of papillation of the rumen wall.

It has been suggested (Hovell, Ørskov, Kyle and MacLeod, 1987) that an increase in protein synthesis and deposition in the gastro-intestinal tract occurs on realimentation which functions to make good the reduction in tissue occurring during restriction (Ryan, 1990). Although dietary protein : energy ratio during restriction led to a simultaneous reduction in the size of the total gastro-intestinal tract relative to EBM, the whole tract remained at the same proportion of EBM during realimentation as during restriction. These results are concordant with the constant digestibility of the HP diet on realimentation from weeks 1,4 through to 8 . They suggest that previously observed effects of a large increase in apparent digestibility of realimentation (Thornton, Hood, Jones and Re, 1979), are very shortlived and are due primarily to increased intake and gut fill.

\section{Acknowledgements}

We thank Drs J. A. Milne, A. J. F. Russel and I. A. Wright for comments and discussion and D. Sim and A. Smith for practical assistance. 


\section{References}

Asplund, J. M., Hedrick, H. B. and Haugebak, C. D. 1975. Performance, digestibility and ${ }^{40} \mathrm{~K}$ levels in lambs during compensation for feed restriction. Tournal of Animal Science 40: $138-143$.

Chowdhury, S. A., Ørskov, E. R., Hovell, F. D. DeB. and Mollison, G. 1991. Protein utilization during energy undernutrition in the ruminant. Proceedings of the sixth international symposium on protein metabolism and nutrition Herning, Denmark, pp. 154-157.

Doney, J. M., Milne, J. A., Maxwell, T. J., Sibbald, A. M. and Smith, A. D. M. 1988. The effects of live weight at weaning on growth rate and carcass composition at different stages of maturity in Scottish Blackface lambs fed on two different diets. Animal Production 47: 401-409.

Fell, B. F. and Weekes, T. E. C. 1975. Food intake as a mediator of adaptation in the ruminal epithelium. In Digestion and metabolism in the ruminant (ed. I. W. MacDonald and A. C. I. Warner), Proceedings of the fourth international symposium on ruminant physiology, Sydney. Australia, pp. 101-118. University of New England, Armidale.

Fattet, I., Hovell, F. D. DeB., Ørskov, E. R., Kyle, D. J., Pennie, K. and Smart, R. I. 1984. Undernutrition in sheep. The effect of supplementation with protein on protein accretion. British Journal of Nutrition 52: 561-574.

Hovell, F. D. DeB., Ørskov, E. R., Kyle, D. J. and MacLeod, N. A. 1987. Undernutrition in sheep. Nitrogen repletion by $\mathrm{N}$-depleted sheep. British Journal of Nutrition 57: 77-88.

Iason, G. R., Mantecon, A. R., Milne, J. A., Sim, D. A., Smith, A. D. M. and White, I. R. 1992. The effect of pattern of food supply on performance, compensatory growth and carcass composition of Beulah and Welsh Mountain lambs. Animal Production 54: 235-241.
Lawes Agricultural Trust. 1984. GENSTAT V, mark 4.04. Rothamsted Experimental Station, Harpenden.

Murray, D. M. and Slezacek, O. 1980. Growth rate effects on some offal components of sheep. Journal of Agricultural Science, Cambridge 95: 241-250.

Murray, D. M. and Slezacek, O. 1988a. The effect of weight stasis on the dissected carcass composition of crossbred sheep. Australian Journal of Agricultural Research 39: 645-651.

Murray, D. M. and Slezacek, O. 1988b. The effect of weight stasis on the non-carcass components of crossbred sheep. Australian Journal of Agricultural Research 39: 653-658.

O'Donovan, P. B. 1984. Compensatory gain in cattle and sheep. Nutrition Abstracts and Reviews Series B 54: 389-410.

Ryan, W. J. 1990. Compensatory growth in cattle and sheep. Nutrition Abstracts and Reviews Series B, 60: 653-664.

Snedecor, G. W. and Cochran, W. G. 1980. Statistical methods. Iowa State University Press, Ames, Iowa.

Thornton, R. F., Hood, R. L., Jones, P. N. and Re, V. M. 1979. Compensatory growth in sheep. Australian Journal of Agricultural Research 30: 135-151.

Turgeon, O. A., Brink, D. R., Bartle, S. J., Klopfenstein, T. J. and Ferrell, C. L. 1986. Effects of growth rate and compensatory growth on body composition in lambs. Journal of Animal Science 63: 770-780.

Vipond, J. E., King, M. E., Ørskov, E. R. and Wetherill, G. Z. 1989. Effects of fish-meal supplementation on performance of overfat lambs fed on barley straw to reduce carcass fatness. Animal Production 48: 131-138.

Wilson, P. N. and Osbourn, D. F. 1960. Compensatory growth after undernutrition in mammals and birds. Biological Reviews 35: 324-363.

(Received 22 April 1992-Accepted 10 August 1992) 